\title{
Democracia interna de los partidos políticos: concreción en Costa Rica y desafíos de reforma para España
}

\author{
Luis Antonio Sobrado González* \\ Wendy González Araya**

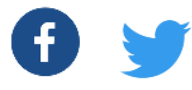 \\ DOI 10.35242/RDE_2019_27_4
}

Nota del Consejo Editorial

Recepción: 30 de octubre de 2018.

Revisión, corrección y aprobación: 10 de diciembre de 2018.

Resumen: El imperativo relativo a la estructuración y el funcionamiento democráticos de los partidos políticos, incorporado en la Constitución española de 1978, fue acogido (en términos casi idénticos) por la Constitución Política costarricense, en donde se introduce por una enmienda de finales del siglo XX. A partir del encuadramiento teórico de la cuestión, como asunto preliminar, la ponencia examinará cómo ese imperativo constitucional fue entendido y desarrollado en la Costa Rica de la primera década del siglo XXI por la jurisprudencia del Tribunal Supremo de Elecciones, la manera en que esa creación pretoriana fue posteriormente concretada en el Código Electoral de 2009 y, luego, revisará las lecciones aprendidas y los aspectos pendientes de la reforma adoptada. El examen de caso permitirá finalmente reflexionar sobre los desafíos que esta evolución sugiere en el contexto español.

Palabras clave: Democracia interna del partido político / Autorregulación partidaria / Organización del partido político / Partidos políticos / Reformas electorales / Jurisprudencia electoral / Justicia electoral / Costa Rica / España.

Abstract: The imperative regarding the structuring and democratic functioning of political parties, incorporated in the Spanish Constitution of 1978, was accepted (in almost identical terms) by the Costa Rican Political Constitution, where it is introduced by an amendment of the late twentieth century. From the theoretical framework of the matter, as a preliminary issue, the paper will examine how that constitutional imperative was understood and developed in Costa Rica in the first decade of the 21st century by the jurisprudence of the Supreme Electoral Tribunal, the way in which that praetorian creation was later specified in the Electoral Code of 2009 and, later, it will review the lessons learned and the pending aspects of the adopted reform. The case study will finally allow us to reflect on the challenges that this evolution suggests in the Spanish context.

Key Words: Internal democracy of political party / Party self-regulation / Organization of political party / Political parties / Electoral reforms / Electoral jurisprudence / Electoral justice / Costa Rica / Spain.

\footnotetext{
* Costarricense, abogado, correo Isobrado@icloud.com. Licenciado y doctor en Derecho por la Universidad de Costa Rica y la Universidad Complutense de Madrid, respectivamente. Magistrado propietario del TSE a partir de 1999. Ocupa la presidencia del organismo electoral costarricense desde el año 2007 y es el director de su Revista de Derecho Electoral. Con anterioridad a su ingreso al TSE, había desempeñado otros cargos públicos en la Procuraduría General de la República y en el Ministerio de la Presidencia. Tiene más de tres décadas de ser profesor de Derecho Constitucional en la Universidad de Costa Rica y desde 1993 coordina la respectiva cátedra de su Facultad de Derecho.

** Costarricense, abogada, correo wgonar@icloud.com. Licenciada en Derecho por la Universidad de Costa Rica. Máster en Ciencias Jurídicas Avanzadas por la Universidad Pompeu Fabra de Barcelona y máster en Abogacía por la Escuela de Estudios Superiores (IDEC) y la Universidad Pompeu Fabra. Actualmente es postulante del doctorado en Derecho de la Universidad Pompeu Fabra, Barcelona. Fue Letrada del Tribunal Supremo de Elecciones.
} 


\section{DERECHO ELECTORAL}

Luis Antonio Sobrado González y Wendy González Araya

PRIMER SEMESTRE 2019 NÚMERO 27

ISSN: 1659-2069

\section{CRISIS de los PARTIdOS Y LA DEMOCRACIA INTERNA COMO PROPUESTA DE CAMBIO}

Las democracias modernas son democracias de partidos: estos cumplen una función fundamental, la cual es vincular la sociedad y el Estado. Sociológicamente, sin embargo, la era de la democracia de partidos parece haber pasado (Mair, 2013, p. 1) dada la creciente indiferencia/antipatía ciudadana.

Su oligarquización es patente desde la aparición de los partidos de masas (Michels, 1973 y Ostrogorsky, 2008). Su burocratización se ha ido consolidando durante los siglos XX y XXI: el afiliado ha pasado a un segundo plano frente a los cargos partidarios y a la actividad mediática de los dirigentes, que se separan de las bases y de la antigua militancia basada en el compromiso cotidiano (Carreras, 2004, p. 94). La organización se centra más en el éxito electoral que en representar los intereses ciudadanos y olvida las normas de responsiveness y accountability (Katz y Mair, 1995).

Existe mediano acuerdo en que la democracia interna partidaria (DIP) puede paliar la crisis de legitimidad de los partidos (Van Biezen et al., 2012), aunque se debe procurar no debilitarlos como organización ${ }^{1}$. De ahí que se hayan impulsado en las últimas décadas reformas en la estructura y prácticas internas. Su adopción, sea por voluntad de las propias agrupaciones o por disposición legislativa, responde (Sobrado, 2017) a razones tanto externas (verlos como instituciones oligárquicas conduce a bajos niveles de confianza ciudadana y de rendimiento electoral) como internas (exigencias de las bases y facciones no hegemónicas para tener peso en la conducción partidaria).

\section{MARCO TEÓRICO}

No es sencillo definir la DIP. Es un "concepto esencialmente disputado" (Gallie, 1984) y dependerá de la idea de democracia que se tenga. Suma a la complejidad del asunto la indeterminación del demos en los partidos (Katz y Cross, 2013, p. 7).

\footnotetext{
${ }^{1}$ La Comisión de Venecia señala que cualquier límite fundado en la DIP debe cumplir con las condiciones del test de proporcionalidad: el límite debe ser adecuado para aumentar la democracia. Debe ser necesario y lo menos perjudicial para la libertad del partido; finalmente, los beneficios para la democracia que se deriven de la restricción deben superar el daño potencial a la libertad.
} 


\section{DERECHO EIECTORAL}

Es posible identificar tres ejes en la DIP2: el derecho de asociación, el derecho de participación-deliberación y la representación, especialmente en sus tres dimensiones (inclusividad, receptividad y rendición de cuentas).

El paradigma de la DIP supone partidos más participativos, deliberativos, inclusivos y transparentes. A razón de indicadores específicos y sin pretender ser exhaustivos, los siguientes son mecanismos deseables (Sobrado, 2017):

- Organización: La composición, la periodicidad y las formas de elegir las estructuras internas de los partidos deben ajustarse a criterios participativos y de visualización de la diversidad partidaria. En su relación con esa colectividad, la dirigencia ha de sujetarse a los principios de alternancia, transparencia e interdicción de la arbitrariedad.

- Selección de candidaturas: Se valoran las convenciones o primarias como instrumentos para la participación de las bases.

- Decisiones: En lugar del modelo de decisiones tomadas por un líder o por un pequeño grupo, se prefieren esquemas de mayor participación de las bases.

- Inclusión: Se adoptan las cuotas o la paridad (en las estructuras partidarias y listas electorales) para potenciar la participación femenina, así como la representación de jóvenes, grupos étnicos y otras minorías.

- Rendición de cuentas: Se establecen fórmulas para exigirla de los candidatos, las autoridades partidistas y los designados en cargos públicos.

Pero aun definiendo ejes generales o indicadores específicos que orienten el análisis, surgen otros problemas: ¿debe enfatizarse la democratización en el resultado, en el proceso o en ambos?; por ejemplo: ¿debe ser inclusivo en participantes el proceso de selección de candidatos o la diversidad debe estar en los candidatos seleccionados o en ambos? La situación se complejiza cuando se analiza la interrelación de los diversos procedimientos

\footnotetext{
${ }^{2}$ Los Lineamientos sobre la Regulación de los Partidos Políticos de la Comisión de Venecia detallan aspectos claves de la DIP: igualdad de género, papel de las minorías, configuración de las reglas internas con procesos participativos y garantías de impugnación, elección de la dirigencia y candidatos del partido y derecho a la afiliación.
} 


\section{DERECHO ELECTORAL}

partidarios en los que se instrumentalizan esas dimensiones. Por ejemplo, el dilema entre los valores participación e inclusión (Hazan y Rahat, 2010) se evidencia en que, según los estudios empíricos, el esquema participativo de primarias es menos conveniente para la inclusión de candidatas.

La conceptualización de la DIP no puede realizarse en forma aislada, pues se trata de un fenómeno sistémico, modulado por las particularidades del sistema electoral, del sistema de partidos y del tipo de partido que se trate. Por ejemplo, los sistemas proporcionales con distritos multinominales hacen más fácil la incorporación de los diferentes grupos en la lista electoral, mientras que los mayoritarios con distritos uninominales se asocian a la baja representación de los colectivos políticamente marginados (Lijphart, 1995, p. 199). Las listas bloqueadas y cerradas tampoco los favorecen y producen una baja accountability de los representantes. En cambio, las listas abiertas y el voto preferencial amplían la capacidad de escogencia del elector, como también podrían mejorar las posibilidades de elección de esos colectivos y la rendición de cuentas, pero a un alto costo especialmente para el partido (Santamaría, 1996, p. 55) ${ }^{3}$.

No hay una fórmula mágica para la DIP. Involucra ejes de análisis complejos, que son en sí mismos categorías abiertas con un contenido difícil de determinar, porque el legislador escoge entre diferentes modelos democráticos y la potestad autorregulatoria de los partidos supone la posibilidad de adoptar diferentes mecanismos para instrumentalizarlos. De ahí que sea difícil hablar de un modelo ideal o mínimo, porque se encuentra ligado a la escala de valores democráticos que maneje cada partido (Katz y Cross, 2013, p. 3).

Aun así, es incuestionable que, para garantizar la fidelidad de los representantes populares respecto de los anhelos políticos del grupo que contribuyó a su elección, resulta esencial que su postulación sea fruto de un proceso transparente en el seno de un partido organizado democráticamente; de lo contrario, el pueblo se encontraría secuestrado por aristocráticas dirigencias partidarias que impondrían arbitrariamente candidaturas (Sobrado, 2007, p. 10).

\footnotetext{
3 Sobre los efectos no deseados, pero altamente nocivos (para los partidos y la calidad de la contienda electoral) que en la práctica ha conllevado el voto preferencial en países de América Latina, ver la sección especial del número 15 de la Revista de Derecho Electoral del TSE (http://www.tse.go.cr/revista/articulos15.htm).
} 


\section{DERECHO ELECTORAL}

\section{CONSTITUCIONALIDAD DE LA DEMOCRACIA INTERNA PARTIDARIA EN ESPAÑA Y COSTA RICA}

La constitucionalización de los partidos políticos, en la Europa de la segunda mitad del siglo XX, estuvo motivada por el repudio al totalitarismo y por la aceptación de la idea de que la democracia pluralista sólo es realizable por el concurso de varios partidos (Sartori, 1987, p. 35). Como reflejo interno de este postulado, se diseñaron fórmulas constitucionales para sujetarlos a formas y sistemas de control que garantizaran que su estructura y funcionamiento interior también fueran democráticos ${ }^{4}$, para atraparlos en las redes del derecho ${ }^{5}$ (Von Alemann, 1981, p. 126).

Así, abatido el nazismo, se promulgó la Ley Fundamental de Bonn (1949). El contexto explica la adopción de distintos mecanismos de resguardo democrático como el contemplado en el artículo 21 sobre el régimen constitucional de los partidos, que incluye la exigencia de que su organización interna responda a "los principios democráticos" como, también, la posibilidad de disolverlos si atentan contra la democracia y la libertad.

Esa definición constitucional fue capitalizada por España (Pegoraro, 2005). Su transición democrática culminó con la promulgación de la Constitución de 1978 (CE), cuyo artículo 6 fue influenciado por la Ley Fundamental de Bonn, al sujetar a los partidos al principio democrático:

Artículo 6: Los partidos políticos expresan el pluralismo político, concurren a la formación y manifestación de la voluntad popular y son instrumento fundamental para la participación política. Su creación y el ejercicio de su actividad son libres dentro del respeto a la Constitución y a la ley. Su estructura interna y funcionamiento deberán ser democráticos.

Dos décadas después, esta norma trascendió a la Constitución Política de Costa Rica. Bajo el impulso del Tribunal Supremo de Elecciones (TSE), en

\footnotetext{
${ }^{4}$ Constitución Italiana (1947), artículo 49; la Ley Fundamental de Bonn (1949), artículo 21; la Constitución de la República Francesa (1958), artículo 4; la Constitución Portuguesa (1976), artículos 10, 40 y 117; la Constitución Griega (1975), artículo 29; y la Constitución Española (1978), artículo 6.

${ }^{5}$ En el ya citado Estudio 721/2103 (p. 7), la Comisión de Venecia identifica tres categorías de países: los que tienen legislación específica sobre partidos políticos, pero no normas sobre la DIP; los que tienen legislación sobre partidos y están enfocados en la DIP, pese a que el detalle puede variar considerablemente de uno a otro país (por ejemplo Alemania, España y Costa Rica); y los que carecen de regulación sobre partidos y generalmente aplican la legislación sobre asociaciones.
} 


\section{DERECHO EIECTORAL}

1997 se agregó un segundo párrafo al numeral 98 constitucional, en el que se transcribió (en términos casi idénticos) el precepto español.

Esa variación no se basó en una traumática experiencia autoritaria, pues ya ese país centroamericano tenía medio siglo de andamiento democrático. Se expone, más bien, un deseo por vigorizar a los partidos e imponerles una estructura a tono con la filosofía republicana (página 13 del expediente legislativo $n .^{\circ} 12138$ ).

La sujeción constitucional de los partidos a la DIP encasilla a estos tres países en el modelo de democracia sustantiva, diferente al liberal, en el que está justificada la imposición de límites al derecho de autorregulación partidaria en procura del fin constitucional ${ }^{6}$.

A pesar de la identidad textual de los preceptos español y costarricense, asociados a su vez en la Ley Fundamental de Bonn, estos han tenido diversa concreción. Esta ponencia pondrá de manifiesto el protagonismo que también tuvo el TSE en el desarrollo de ese postulado constitucional, lo que luego se confrontará con la realidad española.

\section{COSTA RICA}

La Constitución Política de 1949 es la primera de la historia costarricense en aludir a los partidos al prever, en su artículo 98, que los ciudadanos "tienen derecho a agruparse" en ellos "para intervenir en la política nacional". De ahí que se le considere como el inicio de un abordaje constitucional de las elecciones como contiendas partidizadas (Sobrado, 2010, pp. 16-17).

No fue hasta 1997 cuando el constituyente derivado apostó por la DIP. La comentada reforma constitucional se reforzó con la adición, también ese año, del inciso 8) al artículo 95 constitucional: "La ley regulará el ejercicio del sufragio de acuerdo con los siguientes principios: [...] 8.- Garantías para la designación de autoridades y candidatos según los principios democráticos y sin discriminación por género".

Estas modificaciones constitucionales, sin embargo, no se acompañaron del respectivo desarrollo legal. Por ello, a partir de 1999, el TSE corrigió una

\footnotetext{
${ }^{6}$ El mismo estudio 721/2013 de la Comisión de Venecia diferencia entre los sistemas de selección de candidatos basados en una visión "liberal" de la democracia (que enfatiza la autonomía de los partidos con poca regulación) y aquellos que asumen valores democráticos "sustantivos", reflejados en una regulación más intensa.
} 


\section{DERECHO EIECTORAL}

serie de prácticas partidarias que, respetando las apariencias jurídicas, traicionaban el imperativo relativo a la DIP. Lo hizo en su condición de juez constitucional especializado en la materia electoral, sentando jurisprudencia en casos contenciosos y también mediante sentencias interpretativas (para lo que echó mano de su potestad constitucional de interpretar, exclusiva y obligatoriamente, las normas electorales).

\subsection{DesarRollo JURISPRUDENCIAL}

A continuación, se abordan las resoluciones del TSE más emblemáticas al respecto, agrupadas en tres ejes: participación, transparencia e inclusión.

a. Participación:

- Recurso de amparo electoral: El Código Electoral vigente en 1997 no proporcionaba una vía procesal idónea para resolver las disputas internas de los políticos ni, en particular, para combatir las arbitrariedades de sus cúpulas, dejando con ello desguarnecido el derecho fundamental a la participación política de la militancia. Invocando el cambio constitucional, la sentencia n. ${ }^{\circ}$ 303-E-2000 ${ }^{7}$ del TSE colmó la laguna legal aplicando analógicamente las reglas del recurso de amparo que tramita la Sala Constitucional. De esa forma nació, pretorianamente, el recurso de amparo electoral en manos del TSE. Un recurso que ha fomentado la DIP, al permitir cuestionar decisiones antes inatacables $y$, en general, garantizar mejor los derechos ciudadanos.

- Renovación de estructuras: Algunos estatutos de los partidos eran omisos en hacer referencia al plazo de nombramiento de sus autoridades. Como consecuencia, las designaciones se presumían vitalicias. La resolución n. ${ }^{\circ}$ 1536-E-2001 determinó que los partidos "acorde con el principio de democratización interna, deben renovar periódicamente sus estructuras internas. No puede aceptarse como válido que las designaciones de los asambleístas tengan carácter vitalicio o indefinido. En este caso deberá el partido ajustar su estatuto, en el sentido de establecer un plazo y mecanismo que satisfaga sus propios intereses,

\footnotetext{
7 Los últimos dígitos identifican el año en que se adoptó la resolución. En razón de que los fallos dictados en el año 1999 omitían esa referencia, las citaremos con indicación de su fecha. Todas las sentencias pueden consultarse en el sitio web del TSE (www.tse.go.cr).
} 


\section{DERECHO ELECTORAL}

siempre y cuando no supere el plazo máximo de cuatro años que marca el ciclo del período electoral costarricense". Es decir, el TSE recordó que la participación política de los ciudadanos agrupados en partidos sólo puede ser efectiva si las decisiones son el resultado de un proceso que inicie desde su base y que propicie la "circulación" de sus élites.

- Imposibilidad de dejar sin efecto las candidaturas postuladas por consulta popular: Así lo estableció la resolución n. $1671-\mathrm{E}-2001$, al señalar que la voluntad superior de las bases no puede ser ignorada por los órganos representativos del partido, incluida su asamblea superior.

- Derecho al voto secreto en las elecciones internas: EI TSE, por sentencia n.0 4130-E1-2009, eliminó la práctica tolerada de recurrir a votaciones a mano alzada o por "aclamación" en las asambleas partidarias que seleccionan candidatos. Consideró que, en ese contexto, la secretividad del sufragio también es inexcusable para proteger la libre expresión de la voluntad de los asambleístas en un marco de DIP.

b. Transparencia:

- Derecho de petición y pronta respuesta: EI TSE ha definido como un derecho fundamental de los militantes, tutelable por la vía del amparo electoral, el que estos puedan formular peticiones y que reciban pronta respuesta por parte de las autoridades partidarias. Desde su resolución n. ${ }^{\circ}$ 0957-E-2001, determinó que están en la obligación "de contestar la gestión, aunque no necesariamente de acceder a lo pedido", al ser ese un mecanismo esencial para transparentar la información partidaria y para el ejercicio genuino de los derechos políticos de la militancia.

- Procesos internos deben reglarse anticipadamente: La jurisprudencia electoral ha insistido en que una de las condiciones esenciales en una contienda electoral, incluidas las intrapartidarias, es la definición previa y transparente de las reglas que la regirán, por lo que deben ser adoptadas y difundidas antes de que la competencia dé inicio (ver sentencia n. ${ }^{\circ}$ 1532-E1-2017). 


\section{DERECHO EIECTORAL}

- Acceso al registro de militantes: Como una garantía de transparencia partidaria, el TSE dispuso que los correligionarios pueden acceder irrestrictamente al listado de afiliados del partido, por ser una condición indispensable para un activismo político eficaz (sentencia n. ${ }^{\circ} 2132-E 8-2017$ ).

c. Inclusión:

- Participación femenina: En 1996, el anterior Código Electoral fue reformado para establecer el deber de contemplar un mínimo del $40 \%$ de mujeres en las estructuras partidarias y en las listas electorales. En los comicios de 1998, aunque los partidos respetaron ese $40 \%$ en las listas globalmente consideradas, la tendencia fue ubicar a las candidatas en sus últimos lugares. En su sentencia n. ${ }^{\circ} 1863$ del 23 de setiembre de 1999, el TSE interpretó que ese $40 \%$ también debía reflejarse en los "puestos elegibles" de las nóminas (según el promedio resultante del historial electoral de cada partido), bajo pena de excluir la respectiva lista de candidatos. Cabe aclarar que, a partir de 2009, rige el principio de paridad con alternancia. Este fue interpretado en la resolución n. ${ }^{\circ} 3603-E 8-2016$, al precisar que, además de la alternancia vertical en las listas, sus encabezamientos también deben ser paritarios.

- Cobro de inscripción de precandidaturas y plazos de militancia previa: Por los efectos discriminatorios que comportan, contrarios a la filosofía de inclusión democrática, las resoluciones n. ${ }^{\circ}$ 303-E-2000 y n. ${ }^{\circ}$ 0859-E-2001 del TSE consideraron que, condicionar la inscripción de precandidaturas al pago de sumas pecuniarias excesivas 0 a plazos desproporcionados de militancia previa, vulnera el derecho fundamental de participación política.

\subsection{Concreción en el Código Electoral de 2009}

Más de una década después de incorporada la regla constitucional que impone la DIP, la Asamblea Legislativa promulgó un nuevo Código Electoral (Ley $n .{ }^{\circ} 8765$ ) que la recoge y expande. 


\section{DERECHO ELECTORAL}

Así, su artículo 50 estipula que:

En su organización y actividad, los partidos políticos deberán regirse por sus propios estatutos, siempre que se respete el ordenamiento jurídico, los principios de igualdad, de libre participación de los miembros y demás fundamentos democráticos. El cumplimiento de estos principios será vigilado por el TSE y lo resuelto por este en esas materias será de acatamiento obligatorio para los partidos políticos ${ }^{8}$.

La ley introdujo reglas que especificaron este postulado. Varias significaron la recepción de la comentada jurisprudencia electoral (el Código Electoral tuvo, como base de discusión, el proyecto que propuso el TSE en 2001 y este tuvo gran presencia en los debates parlamentarios).

Por ejemplo, el numeral 48 establece que "solo pueden participar individualmente, 0 en coalición, los partidos inscritos que hayan completado su proceso democrático de renovación periódica de estructuras y autoridades partidistas" y el inciso j) del artículo 52 estipula que, aunque la asamblea superior de un partido político es la que define o ratifica a los candidatos, su intervención se exceptúa cuando sean escogidos en convenciones internas.

Especial relevancia tuvo el desarollo legal que consolidó la jurisdicción electoral a cargo del TSE y, en ese marco, la regulación del recurso de amparo electoral que, como veíamos, tuvo un origen pretoriano nueve años antes.

\subsection{LECCIONES APRENDIDAS Y PENDIENTES DEL CASO COSTARRICENSE}

El replanteamiento de los partidos, para perfilarlos como organizaciones más claramente democráticas, fue el resultado de un largo proceso propiciado por el TSE: impulsó la respectiva reforma constitucional de 1997, acondicionó jurisprudencialmente la legislación vigente en ese momento y propuso el Código Electoral en vigor desde 2009, al que se incorporaron las reseñadas definiciones jurisprudenciales.

Tres factores explican su éxito: la apuesta democrática del TSE, su amplia credibilidad ciudadana y la fortaleza institucional que le otorga su diseño

\footnotetext{
${ }^{8}$ En la misma dirección se orientan el inciso f) de su artículo 12 y el inciso d) del 54 .
} 


\section{DERECHO ELECTORAL}

constitucional; todo lo cual se conjuga para potenciar sus posibilidades de definir e implementar una política pública como la que nos ocupa.

Sobre el último factor indicado, conviene recordar que la Constitución Política del país se alinea al modelo latinoamericano de institucionalidad electoral, que supone órganos constitucionales permanentes y especializados que gestionan autónomamente la función electoral. En el caso costarricense, el TSE ostenta el rango e independencia de los poderes del Estado, centraliza la administración y la justicia electorales y se le adscribe el Registro Civil.

Esta evolución ha coincidido en el tiempo con un lamentable proceso de debilitamiento de los partidos; retroceso que desafía de modo singular a la sociedad costarricense, toda vez que las democracias consolidadas suelen tener partidos fuertes detrás.

Diversos factores han conducido, desde finales del siglo pasado, a una transformación del régimen de partidos. No solo se manifiestó en la ruptura del bipartidismo tradicional. También se tradujo en una merma significativa de la tasa histórica de participación electoral y en una marcada volatilidad de las preferencias políticas (particularmente intensa en las elecciones presidenciales de 2014 y 2018), que ahora se definen más por las condiciones de los candidatos que por la bandera que los postula. Fenómeno que expresa la erosión de las lealtades partidarias, la crisis de confianza en las agrupaciones políticas y una mayor personalización de la política (Sánchez, 2007).

A esto se suma un crecimiento desmedido del registro de partidos políticos (alrededor de 100 en un país de poco más de tres millones de electores), alentado por incentivos perversos que contiene la legislación. Aun las agrupaciones tradicionales han ido perdiendo músculo organizativo, presencia en época no electoral y capacidad para generar pensamiento político y relevo generacional de su liderazgo. Debilidad que también se asocia a una mayor incidencia del transfuguismo político.

\section{España}

El régimen de los partidos y el desarrollo legislativo de la DIP reflejan una realidad política específica influenciada, entre otros, por el sistema de gobierno, de partidos y el electoral. La finalidad de esta ponencia no es trabar un análisis comparativo, por tratarse de realidades tan diferentes; se trata, más bien, de evidenciar la evolución en dos ordenamientos de una 


\section{DERECHO ELECTORAL}

norma constitucional casi idéntica. Esta labor podría resultar útil de cara a propuestas de lege ferenda, para aprender de las diferencias.

La naturaleza jurídica de los partidos desde una perspectiva constitucional determina, en gran medida, la construcción de un derecho de partidos, por parte del legislador y del operador jurídico. En el caso español y de acuerdo con su Tribunal Constitucional, los partidos son entes privados sometidos al régimen de las asociaciones (STC 3/1981, STC 10/1983), pero se les aplica una legislación específica, cuya base constitucional se encuentra en la relación del artículo 22 CE (derecho de asociación) y el artículo 6 CE (funciones de los partidos y exigencias de democratización).

La construcción del régimen de partidos con base en el derecho de asociación política y no en el derecho de participación política (STC 85/1986) tiene consecuencias esenciales en el fortalecimiento de su organización y funcionamiento interno, asegurando el menor control e intervención estatal y dando gran importancia (incluso prevalencia) a la unidad jurídica y moral de la asociación manifestada en la potestad de autorregulación partidaria (STC 218/1989). El afiliado se encuentra integrado en la unidad de la asociación y afecto a un deber de lealtad que supone el cumplimiento de normas internas y fines perseguidos por el partido, los que se entienden aceptados voluntariamente por la sola afiliación.

La DIP se plasma en la exigencia de que los partidos se rijan por reglas que permitan la participación de los afiliados en la gestión y control de los órganos de gobierno, mediante el reconocimiento de derechos y atribuciones a los afiliados (STC 56/1995). Estos deben ser configurados por el legislador, quien cuenta con un amplio margen de libertad para optar por diversos modelos (Requejo Pagés, 2001 y Pérez-Moneo, 2012).

A continuación, analizaremos cómo se desarrollaron en el modelo español algunas de las medidas de DIP adoptadas en el costarricense.

\subsection{El RECURSO de AMPARO EN RELACIÓn CON LA TUTELA DE LOS DERECHOS DE LOS AFILIADOS}

El sistema español contempla un recurso de amparo ordinario que protege frente a las vulneraciones de los derechos y libertades reconocidos en los artículos 14 a 29 y 30.2 de la CE y un recurso de amparo electoral, contemplado en la LO 5/1985 del Régimen Electoral General contra los Actos de las Juntas Electorales sobre la proclamación 


\section{DERECHO ELECTORAL}

o exclusión de candidatos y candidaturas (art. 49.3) y contra la proclamación de electos y elección y proclamación de presidentes de las corporaciones locales (art. 114.2), que solo tutela el derecho de sufragio, en su dimensión pasiva en órganos representativos, que supone el previo agotamiento de la vía contencioso administrativa.

Los derechos de asociación política partidaria tutelados en el artículo $22 \mathrm{CE}$, regulados en los artículos 6, 7 y 8 de la Ley Orgánica 6/2002, de 27 de junio, de partidos políticos (LOPP), son el núcleo de la garantía de DIP (STC 56/1995); los derechos que se deduzcan de estas normas son amparables por la vía constitucional ordinaria, lo que supondría también el agotamiento de la vía judicial civil (STC 154/1988) y el demostrar "especial trascedencia constitucional del recurso". El juez constitucional delineó las reglas del estatuto jurídico del afiliado: 1) los derechos constitucionales de participación política de los afiliados son derechos de configuración legal y, por eso, se limitan a los contenidos en la LOPP, 2) los estatutos partidarios pueden ampliar los derechos de participación y control de sus afiliados, en el marco de la CE y la ley; sin embargo, esos derechos añadidos serán solo derechos de rango estatutario.

Se crean, entonces, dos categorías de derechos de los afiliados: los derechos de configuración legal que integran el contenido del artículo $21 \mathrm{CE}$ (tutelables en la jurisdicción constitucional) y los derechos que acojan los estatutos (que deben tutelarse en la jurisdicción ordinaria porque no son derechos constitucionales). En la vía ordinaria la tutela se limita a verificar si existe base razonable de la decisión partidaria, sin entrar a revisar el juicio que los partidos han realizado (STC 218/1988 y STC 226/2016); se trata más de una revisión de procedimiento que de sustancia, en la que prevalece el derecho fundamental a la autorganización de los partidos por encima del derecho del afiliado, quien está sujeto a un deber de lealtad y a la normativa partidaria que se entiende aceptó al asociarse.

La falta de regulación legal de procedimientos partidarios esenciales, como el de selección de candidatos a cargos públicos, provoca que los derechos de los afiliados respecto a funciones esenciales de los partidos tengan carácter meramente estatutario, no tutelables, en principio, en la vía constitucional, porque no se consideran parte del contenido del derecho de asociación política (artículo 22 CE). 


\section{DERECHO ELECTORAL}

\subsection{LA PARTICIPACIÓN PARITARIA DE LA MUJER NO FORMA PARTE DE LA DIP}

La STC 12/2008 examinó una modificación legal en la que se incluyó la obligación de guardar, en las listas electorales, una composición equilibrada de hombres y mujeres, no pudiendo superar cada uno de los sexos el $40 \%$, proporción que se ha de mantener en cada tramo de 5 puestos.

El juez constitucional indicó que no se trata de una medida de discriminación inversa o compensatoria, sino de una fórmula de equilibrio entre sexos que tampoco es estrictamente paritaria, en cuanto no impone una total igualdad, sino un efecto bidireccional para ambos sexos. El balance de sexos es solo otra limitación legal, de acuerdo con el mandato de la norma suprema de promover la igualdad real y efectiva. Así, dispuso que "no impide la existencia de partidos con una ideología contraria a la igualdad efectiva entre los ciudadanos", pues el hecho de que tengan que respetar porcentajes en las listas no implica que el partido deba participar de los valores de la democracia paritaria.

\section{Corolario}

La principal diferencia entre los países estudiados radica en la tutela de los derechos de participación política del afiliado y en la amplitud del desarrollo legal y jurisprudencial de la exigencia de la DIP.

En el caso de Costa Rica, el juez electoral desarrolló el régimen de partidos con base en el derecho de participación política, resaltando el carácter de estos como intermediarios entre la sociedad y el Estado y encauzando la libertad de autoorganización partidaria dentro del marco de la garantía de DIP, en procura de la efectiva participación democrática del afiliado. Estas reglas, posteriormente, fueron adoptadas por el legislador.

Por su parte, el juez constitucional español optó por deducir el régimen de partidos del derecho de asociación política, fortaleciendo la libre autorregulación partidaria y limitando el contenido del derecho fundamental de participación del afiliado a un tímido desarrollo legal de la garantía de la DIP. 


\section{DERECHO EIECTORAL}

\section{REFERENCIAS BIBLIOGRÁFICAS}

Carreras, F. (2004). Los partidos políticos en nuestra democracia de partidos. Revista Española de Derecho Constitucional, (70), 91-126.

Comisión de Venecia (2010). Lineamientos sobre la Regulación de los Partidos Políticos. Recuperado de: http://www.venice.coe.int/webforms/ documents/default.aspx?pdffile $=$ CDL-AD(2010)024-spa

Comisión de Venecia (2015). Report on the method of nomination of candidates wihin political parties. Recupedado de http://www.venice.coe.int/ webforms/documents/default.aspx?pdffile $=$ CDL-AD(2015)020-e

Costa Rica. Asamblea Legislativa (1995). Expediente legislativo n. ${ }^{\circ} 12.138$. Recuperado de http://www.asamblea.go.cr/Centro_de_Informacion/ Consultas_SIL/Pginas/Detalle\%20Proyectos\%20de\%20Ley.aspx?Numero_Pr oyecto $=12138$

Costa Rica (2009). Código Electoral, ley n. ${ }^{\circ} 8765$ del 19 de agosto de 2009, publicado en alcance n. ${ }^{\circ} 37$ a La Gaceta n. ${ }^{\circ} 171$ del 2 de setiembre.

España (1978). Constitución española del 6 de diciembre.

España (1985). Ley Orgánica del Régimen Electoral General, LO 5/1985, publicada el 19 de junio.

España (2002). Ley Orgánica de Partidos Políticos, LO 6/2002, publicada el 27 de junio.

Gallie, W.B. (1964). Essentially Contested Concepts. En Gallie, W. Philosphy and the Historial Understandin. Londres: Chatto and Windus.

Hazan, R. y Rahat, G. (2010). Democracy Within Parties. Candidate Selection Methods and their Political Consequences. Oxford: Oxford University Press.

Katz, Richard y Cross, W. (2013). The Challenges of Intra-Party Democracy. Oxford: Oxford University Press.

Katz, R.y Mair, P. (1995). Changing models of party organization and party democracy: the emergence of the cartel party. International journal for the study of political parties and political organizations, 1(1), 5-28.

Lijphart, A (1995). Sistemas electorales y sistemas de partidos: Un estudio de veinte democracias, 1945-1990. Madrid: Centro de Estudios Constitucionales. 


\section{DERECHO ELECTORAL}

Mair, P. (2013). Gobernando el vacío. La banalización de la democracia occidental. Madrid: Alianza Editorial.

Michels, R. (1973). Los partidos políticos: un estudio sociológico de las tendencias oligárquicas de la democracia moderna. Argentina: Amorrortu Editores.

Ostrogorski, M. (2008). La democracia y los partidos políticos. Madrid: Mínima Trotta.

Pegoraro, L. (2005). El Derecho Comparado y la Constitución Española de 1978. La recepción y exportación de modelos. Anuario Iberoamericano de Justicia Constitucional, (9), 287-321.

Pérez-Moneo, M. (2012). La selección de candidatos electorales en los partidos. Madrid: Centro de Estudios Políticos y Constitucionales.

Requejo, J.L. (2001). Derechos de configuración legal. En Aragón Reyes, M. (ed.). Temas básicos de Derecho Constitucional, pp. 134-136. Madrid: Civitas.

Sánchez, F. (2007). Partidos políticos, elecciones y lealtades partidarias en Costa Rica: erosión y cambio. Salamanca: Ediciones Universidad de Salamanca.

Santamaría, J. (1996). El debate sobre las listas electorales. En Porras Nadales, A. (ed.). El debate sobre la crisis de la representación política, pp. 231264Madrid: Tecnos.

Sartori, G. (1987). Partidos y sistemas de partidos, I. Madrid: Alianza Universidad.

Sobrado, L.A. (2017). Democracia interna. En: Diccionario Electoral, pp. 275281.San José: Instituto Interamericano de Derechos Humanos.

Sobrado, L.A. (2007). Democratización interna de los partidos políticos en Costa Rica. San José: FLACSO.

Sobrado, L.A. (2010). El régimen electoral en la Constitución de 1949. Revista de Derecho Electoral, (9), 29-49.

Van Biezen, I. et al. (2012). Going, going... gone? The decline of party membership in contemporary Europe. European Journal of Political Research, (51), 24-56.

Von Alemann, U. (1981). Democracia de partidos y participación ciudadana. Revista de Estudios Políticos, (20), 119-135. 


\section{DERECHO EIECTORAL}

\section{Jurisprudencia}

Sala Primera del Tribunal Constitucional de España (1981). Sentencia 3/1981 del dos de febrero.

Sala Primera del Tribunal Constitucional de España (1986). Sentencia 85/1986 del veinticinco de junio.

Sala Primera del Tribunal Constitucional de España (1989). Sentencia 218/1989 del veintiuno de diciembre.

Sala Segunda del Tribunal Constitucional de España (1988). Sentencia 218/1988 del veintidós de noviembre.

Sala Segunda del Tribunal Constitucional de España (1995). Sentencia 56/1995 del seis de marzo.

Tribunal Constitucional de España en Pleno (1983). Sentencia 10/1983 del veinticinco de febrero.

Tribunal Constitucional de España en Pleno (1988). Sentencia 154/1988 del veintiuno de julio.

Tribunal Constitucional de España en Pleno (2008). Sentencia 12/2008 del veintinueve de enero.

Tribunal Constitucional de España en Pleno (2016). Sentencia 226/2016 del veintidós de diciembre.

Tribunal Supremo de Elecciones de Costa Rica (2000). Resolución 303-E-2000 de las nueve horas treinta minutos del quince de febrero.

Tribunal Supremo de Elecciones de Costa Rica (2001). Resolución 0957-E-2001 de las nueve horas con veinticinco minutos del dos de mayo.

Tribunal Supremo de Elecciones de Costa Rica (2001). Resolución 0859-2001 de quince horas con treinta minutos del diecisiete de abril.

Tribunal Supremo de Elecciones de Costa Rica (2001). Resolución 1536-E-2001 de las ocho horas del veinticuatro de julio.

Tribunal Supremo de Elecciones de Costa Rica (2001). Resolución 1671-E-2001 de las quince horas del diez de agosto.

Tribunal Supremo de Elecciones de Costa Rica (2009). Resolución 4130-E1-2009 de las quince horas con treinta minutos del tres de setiembre. 


\section{DERECHO ELECTORAL}

Luis Antonio Sobrado González y Wendy González Araya

PRIMER SEMESTRE 2019 NÚMERO 27

ISSN: 1659-2069

Tribunal Supremo de Elecciones de Costa Rica (2016). Resolución 3603-E8-2016 de las diez horas del veintitrés de mayo.

Tribunal Supremo de Elecciones de Costa Rica (2017). Resolución 1532-E1-2017 de las diez horas del veintitrés de febrero.

Tribunal Supremo de Elecciones de Costa Rica (2017). Resolución 2132-E8-2017 de las diez horas del veintiocho de marzo. 